\title{
Research on Strategies and Patterns of Research Teaching
}

\author{
Jianjun Liu
}

\author{
Department of Computer Dezhou University Dezhou China
}

\begin{abstract}
In order to improve teaching level, quality and effect, more and more attention has been paid to the tendency of research teaching being one part of teaching reform in higher education. The research teaching model is proposed that opposite to in unidirectional knowledge instruction teaching model primarily, it refers to the teaching system melting study and research as a body. The research teaching model is the research undergraduate college teaching basic teaching model. Starting with the significance and the conduction of research teaching, this paper puts forward and analyzes several patterns of research teaching, discusses the important role of teachers in these patterns and proposes some strategies as well as suggestions.
\end{abstract}

Index Terms: Research teaching; Pattern; Innovation; Assessment; Strategy

(C) 2012 Published by MECS Publisher. Selection and/or peer review under responsibility of the International Conference on E-Business System and Education Technology

\section{Introduction}

In order to improve teaching level, quality and effect, more and more attention has been paid to the tendency of research teaching being one part of teaching reform in higher education. However, teachers' dominance mustn't be ignored in our efforts of research teaching reform. Therefore, this paper studies and analyzes the conduction of research teaching and its problems in order to further promote its research, application and perfection $^{[1]}$.

\section{Importance of Research Teaching}

Research teaching emphasizes the central role of students during the teaching process as well as a combination of teachers' research teaching and students' research learning, it also pays much attention to combining academic knowledge and research methods. What's more, teachers' dominance and students' principal status are fully exerted by emphasizing students' practical application of the knowledge and techniques they have learnt and their first-hand experience in the learning process.

\footnotetext{
* Corresponding author:

E-mail address: ljj@dzu.edu.cn
} 


\subsection{Cultivating Students' Scientific Learning Attitudes and Innovative Learning Ideas}

In research teaching, students should have careful exploration, draw conclusions based on facts, respect others' achievements. Hence they should develop truth-seeking attitudes towards science as well as pioneering spirit.

\subsection{Improving Students' Comprehensive Analysis Ability}

Questions involved in research teaching cannot generally be solved by single branch of study but comprehensive application of multi-disciplinary knowledge , hence teacher should cultivate students' abilities in interaction and comprehensive analysis and improve their overall quality. With the traditional teaching pattern changing in which knowledge instead of ability and overall quality, students should learn to find rules and questions through their own research learning and practice, grasp basic methods of scientific research and improve their own practical abilities.

\subsection{Establishing Students' Cooperative Sense}

Interaction between teachers and students in research teaching teaches students how to communicate and share their information, ideas and achievements, hence teachers should cultivate their team spirit and improve their comprehensive abilities.

\subsection{Cultivating Students' Communication Skills, Self-expression and Innovation Spirit}

By creating problem situations, research teaching succeeds in changing the forum into a platform for the interaction between teachers and students in which teachers fully respect students' principle role, establishes an equal, loose and harmonious environment to enlighten students and encourage them to solve questions. Through their independent participation in research activities, students gradually develop positive attitudes, such as being ready to ask and explore questions, having practice and pursuing scientific truth and so on. What's more, their wish for exploration and innovation is also be inspired ${ }^{[2]}$.

\section{Understandings of Conduction of Research Teaching}

\subsection{Understanding of Teaching and Learning}

"Teaching" refers to the process in which students' knowledge is increased, their ability is improved and their quality is cultivated, while "research" means the process in which old knowledge is utilized to create new knowledge, to develop new ideas and put forward new theories. Traditional teaching can be reformed with the opinions, methods and processes of research to form "research teaching", it is characterized by an open teaching process, students' important role in it as well as students' independent exploration in problem solving, knowledge and ability acquisition. Teachers serve students with their teaching which equips students with not only knowledge but ability and quality. Even in the process of knowledge learning, not only conclusions but also the background and the process to draw them need to be learnt. Besides, students are also expected to learn methods to explore the world, to cultivate their innovative sense, to develop their own scientific ideas, to develop truth-seeking attitudes and to establish right values. If we say learning is led by teachers in the traditional teaching, teaching is based on learning in this new pattern. Students should be given more opportunities to participate in teaching as well as learning to experience sense of success during the process of research teaching.

\subsection{Understanding of the Subject of Research Teaching}

The core idea of research teaching lies in the central role of students, teachers should encourage their enthusiasm for learning, enhance their interest, ability and innovation sense, develop their potential, enlighten their thinking while conveying knowledge and techniques to promote the improvement of their knowledge, ability and quality. 


\subsection{Understanding of the Conversion of Teachers' Concept}

In research teaching, the change in teachers' duty is the most important, that is, from emphasizing knowledge to emphasizing students' overall development, from emphasizing teaching result to teaching process, from emphasizing teachers' one-way instruction to the cooperation between both teachers and students. The most important task for teachers isn't to convey knowledge but to help students to cultivate their potential, to encourage their enthusiasm for participation in new knowledge creation and to enhance their independent innovation skills.

\subsection{Understanding of Interaction between Teachers and Students}

Research teaching has to involve a large amount of teacher-student interaction to inspire students' enthusiasm. With students being the principle role of the whole teaching and learning process, teachers are expected to share the experience of exploration with students, hence their teaching tasks is help students to acquire knowledge, ability, quality and sense of success. Since teachers may have some mistakes or shortcomings, students will learn from both positive and negative experience. In this sense, the idea of "teaching benefits teachers as well as students" is manifested in research teaching in a better way ${ }^{[3]}$.

\section{Patterns of Research Teaching}

Current research teaching is mainly conducted in the following forms:

\subsection{Project Research}

This is a practical pattern, in which projects can be given by teachers or designed and conducted by students themselves with some necessary instructions. Emphasizing the cultivation of students' independent exploration and practical operation, this pattern is intended to give students opportunities to explore and find answers, to integrate knowledge and develop innovative abilities independently.

\subsection{Cooperative Research}

Cooperative research is intended to solve some problems unsolvable for individual students through group cooperation. In this pattern, a teacher is an organizer, a participant and an instructor. Tasks and questions should be challenging enough to inspire students' enthusiasm and passion for group activities. This pattern will help to form a favorable atmosphere in which teachers and students learn from each other and have emotional communication, hence improving students' cooperative spirit and interpersonal communication.

\subsection{A Combination of Independent Research and Group work}

Based on a topic or a practical problem, some students or an organization conduct research activities together in which individual or united efforts are made to collect materials, to conduct exploratory or design activities, to draw conclusions, form opinions or make achievements, to share elementary achievements with each other, and later to further their study through interaction or draw their research to an end. Such a pattern is suitable for those researches covering a large range because students need some collisions in their thought with others when lacking in an understanding of the nature of a question or failing to form scientific questions.

\subsection{Discussion on Questions}

This pattern is mainly intended to develop students' sense of finding questions and practical abilities of solving questions in order to raise their comprehensive quality and ability. On one hand, this pattern emphasizes the importance of questions in learning and regarding questions as the motivation, starting point and main stream of the learning process; on the other hand, questions are formed through learning and the learning process should be regarded as a period to find, raise, analyze and solve questions. 


\section{Process of Research Teaching}

The teaching process involves interaction between teaching and learning. While strengthening students' principle status, we shouldn't neglect teachers' instructive role, which can be reflected in their grasp over the predictability and gradual steps of class teaching, their ingenious creation of learning circumstances, reasonable allocation of teaching time, coordination of class atmosphere and proper instruction of teaching methods and so on.

\subsection{Planning}

As the schemer of research teaching, teachers are supposed to select teaching contents which reflect the core idea of this branch. After that, they should design their teaching steps, including how to introduce a topic, what to ponder over, how to inspire students' reflection, in what way to explore, how to draw conclusions and so on. all activities should be based on the interaction between teachers and students to reflect students' principal role, to inspire their potential and to exert their innovative abilities.

\subsection{Organizing}

Here, not only the organization of the whole teaching process but that of certain teaching section should be included. Some inspiring words can be used to organize the teaching process to improve students' thinking, to encourage those inactive students to speak out their opinions and those innovative ones to share their good ideas as well as to eliminate their worry about mistakes, so teachers should help students produce perfect answers or conclusions through discussion, argument, summery and refinement. In addition, with greater passion for interaction and discussion between teachers and students, a truth-seeking research atmosphere can be created in which most students are good at pondering and brave to express themselves, promoting their research and exploration advancing in the right direction.

\subsection{Guiding Students}

As a guide, teachers play a significant role in improving students' mode of thinking as well as their trait of thinking. They are expected to create circumstances under which students find, raise and explore questions, to unlock students' potential with their designed words and to encourage students' mutual illumination through their discussion. In addition, they should try to enable students to experience open thinking, divergent thinking, dynamic thinking, overall thinking, difference-seeking thinking, query thinking, critical thinking and creative thinking during research teaching. Actually, it is the most important to develop students' habits of breaking the rules and advancing new ideas ${ }^{[6]}$.

\subsection{Training Students}

Covering a relatively long period, research teaching calls for students' active coordination. Therefore, spiritual encouragement in different aspects will exert favorable effects. With proper encouragement of this kind, research teaching will go more smoothly.

\subsection{Giving Encouragement}

In addition to the above, teachers should also give encouragement in the modes and contents of assessment to make research teaching more popular with both teachers and students. It is very important that teachers should appreciate students' questioning and have discussion with them equally. In addition, some on-the-spot comments on the advantages of research teaching should be made to enable students to recognize and become interested in research teaching, to develop right values, strong thirst for knowledge and truth-seeking attitudes. 


\subsection{Giving Summary}

With many possible questions during research teaching, teachers should be good at pre-setting questions, finding questions, solving questions and summarizing experiences to enable such a teaching pattern to be more impressive and to make greater advance ${ }^{[5]}$.

\section{Some Important Issues on Research Teaching}

\subsection{Reorienting our Education Idea}

Not only the teaching objectives but also the relationship between teachers and students should be reoriented. It has been the main goal for college teaching to cultivate students' scientific spirit, scientific research methods and scientific morality through research teaching. Teachers, the key to our success, need to convert from their traditional role of delivering knowledge to a new one of cultivating students' initiative and innovative abilities, from the educator to the learner and inventor.

\subsection{Improving Former Teaching Contents and Methods}

Research teaching is a process of knowledge innovation, calling for teachers to introduce the latest achievements into class for students to discuss and raise questions and therefore to form new thoughts, new ideas and theories. Practical teaching sections should be increased by reducing testifying and demonstrating experiments and increasing design and comprehensive ones. The former one-fold teaching pattern should give way to a comprehensive one and the individual teaching pattern should also be replaced by a diversified one. For teachers, this is a reconstruction of their own knowledge and ability as well as a fundamental shift in their teaching method, hence beneficial for cultivating advanced talents ${ }^{[7][8]}$.

\subsection{Improving Assessment System}

A proper assessment system is expected to fully examine to what degree students have innovative ideas, different opinions, diversified conclusions and coordinated teamwork with more scientific and reasonable evaluation methods. In the assessment on teachers, more emphasis is focused on their organization and instruction in teaching, reasonableness of the number of students they instruct, their participation in class activities, relevance and innovativeness of their project design and so on.

\subsection{Exchanging Experiences in Research Teaching}

After a term's teaching practice, all the participants should be organized to have a forum, at which every one shares his problems, solutions and suggestions during his research teaching practice. In this way, some good experiences can be spread out, hence promoting research teaching to achieve better and faster development.

\section{Conclusion}

The establishment of research teaching model needs massive research and exploration. The establishment of research teaching model also set new request to reform of teaching management pattern and teaching operational mechanism. The research teaching requests that teaching's mechanism has flexibility, curriculum teacher has more investments, teacher's investment way also shows multiplication. How to carry on reasonable appraisal to curriculum teacher's investments How to carry on the reasonable appraisal to the teaching effect. How to establish the effective incentive mechanism to encourage the teacher to develop the research teaching and so on. They are the question that is worth exploring and researching for us. 


\section{References}

[1] Deng, Cunrui,The Role of Modern Teaching Means in Higher Education Reform. Education and Modernization,Vol.3: pp.47-51,1987.

[2] Gu, Binglin,Innovation: A Way of Success for Research Universities. China Education News,19th November 2007.

[3] Long, Yuejun, Value Reflection and Connotation Interpretation of Research Teaching in Universities. China University Teaching. Vol.6: pp.22-23,2006.

[4] Ruan, Qiuqi. Cultivating Innovative Talents with Research Teaching, China University Teaching, Vol.12: pp23-25,2008.

[5] Wang, Siyu,Reflections on Constructing Teaching and Research Universities,Heilongjiang Education[in Chinese], Vol.10: pp.3-5,2006.

[6] Yuejun Long,Value Resonsideration and Connotation Explanation of Research Teaching in University,University Teaching in China,2006.

[7] Laixiang Sun,Curriculum Reform and Education Innovation of Research University,Beijing : High education publishing press[in Chinese].pp.86-88,2005.

[8] Ligang $\mathrm{Wu}$,Teaching principle pattern and activity,Nanning : Guangxi education publishing press[in Chinese], pp.178-180 1998. 